Article

\title{
Dialogic Feminist Gatherings: Impact of the Preventive Socialization of Gender-Based Violence on Adolescent Girls in Out-of-Home Care
}

\author{
Marifa Salceda $^{1}{ }^{1}$ Ana Vidu ${ }^{2}{ }^{-}$, Adriana Aubert ${ }^{1, *}$ and Esther Roca ${ }^{3}$ \\ 1 Department of Sociology, University of Barcelona, 08034 Barcelona, Spain; \\ marifa.salcedamesa@educantabria.es \\ 2 Department of Private Law, University of Deusto, 48007 Bilbao, Spain; ana.vidu@deusto.es \\ 3 Department of Comparative Education and History of Education, University of Valencia, 46010 Valencia, \\ Spain; esther.roca@uv.es \\ * Correspondence: adriana.aubert@ub.edu
}

Received: 15 June 2020; Accepted: 31 July 2020; Published: 5 August 2020

check for updates

\begin{abstract}
Gender-based violence is a social scourge with an increasing incidence at younger ages. Many studies have focused on finding effective solutions for overcoming this problem; however, few studies have analyzed the contribution of interactive learning environments to gender-based violence prevention. This article attempts to fill this gap by showing the impact of Dialogic Feminist Gatherings on the preventive socialization against gender-based violence toward adolescent girls (aged 15-18) who are in out-of-home care and living in shelters-part of the institutional protection system - for different reasons that are primarily associated with violence and a lack of family protection. This qualitative study was conducted using the communicative methodology involving fifteen daily life stories that analyze the dialogues and reflections produced among the girls during Dialogic Feminist Gatherings. The results show the acquisition of competencies in aspects such as attraction, election, and equality in sexual-affective relationships. These dimensions, when developed through Dialogic Feminist Gatherings, are consistent with the scientific literature that characterized them as protective factors against gender-based violence. This study concludes by contrasting participants daily life reality with scientific evidence, which makes possible new methods of the preventive socialization against gender-based violence for adolescent girls in out-of-home care.
\end{abstract}

Keywords: Dialogic Feminist Gatherings; dialogic reading; gender-based violence; preventive socialization of gender-based violence; out-of-home care; residential care

\section{Introduction}

The disintegration of the family household is one of the factors that the Social Exclusion Unit (2001) considers when assessing the risk of social exclusion because early life experiences and the quality of the contexts surrounding growth and development during childhood substantially affect a child's adult life trajectory. Decades of research on the life trajectories of children in residential care institutions ${ }^{1}$ have demonstrated adverse impacts on cognitive, social, and language development (Lum et al. 2018), as well as severe educational disadvantages (Flynn et al. 2013) and other increasing risk circumstances. Among them is a higher probability of suffering from poverty, homelessness, or increased exposure to violence because of the multiple adversities reflected in their daily life stories

1 This manuscript mentions the concepts of out-of-home care, residential care, residential care institutions to refer to this model of living and care for minors under an institutional protection system. 
(Brännström et al. 2017). Along these lines, several studies revealed a greater risk of suffering from gender-based violence (GBV) (Crooks et al. 2019; Wolfe et al. 2003). GBV is considered one of the most significant current social concerns, not only because of its higher occurrence but also because of its increasing prevalence at younger ages and the fact that it negatively affects the mental and physical health of many victims (Adhia et al. 2019; Puigvert et al. 2019; Racionero-Plaza et al. 2020).

Research evidence in this field pointed out socialization toward violence as a potential indicator of the origin of GBV (Puigvert et al. 2019). However, the socialization process also addresses the possibility to advance toward nonviolence by transforming people's thoughts, attitudes, and behaviors through interactions and dialogues that place the focus of attraction on egalitarian relationships and the best human values and feelings. Along this line, the present manuscript provides evidence of the direct social impact resulting from an educational intervention called Dialogic Feminist Gatherings (DFGs), which aims to overcome and prevent GBV and is conducted with adolescent girls living in a Spanish residential care institution. This intervention involves first reading about topics related to the preventive socialization against GBV (Gómez 2015) and then engaging in sharing dialogues and reflections in an interactive learning environment using a dialogic feminism approach (Botton et al. 2005).

To better describe this intervention and its success, the present manuscript is divided into four sections. The first section analyzes the scientific evidence for the contribution of interactive learning environments to violence prevention and focuses on explaining the functioning of the DFG. The second section describes the methodology conducted, including a description of the research participants and the procedures, categories, and subcategories of the data analysis. The third section addresses the results of the research. Finally, the discussion and conclusions of our study are presented.

\section{Interactive Learning Environments to Prevent Gender-Based Violence}

Education and learning are key factors in GBV prevention (Crooks et al. 2019). The UN Women's report on the transformative potential of Agenda 2030 for gender equality highlights the importance of women's and girls' educational levels in advancing the goal of gender equality, which involves overcoming all forms of violence against women. To this end, this report points out that "each additional year of education beyond primary school has significant multiplier effects for girls, including better employment outcomes for women, reduced likelihood of early marriage, improving health and well-being for themselves and future generations" (UN Women 2018, p. 83). In the context of the COVID-19 pandemic, ${ }^{2}$ a need exists to attend to the survivors of gender and family violence as an emergency issue that already exists but is aggravated by the lockdown. In this sense, important to achieve for these women are valid information, real solutions, and evidence-based contributions (Pulido et al. 2020).

Research on minors in out-of-home care presents solid evidence of the serious educational disadvantages that they usually face (Baldwin et al. 2019; García-Yeste et al. 2018). The academic expectations and the level of involvement and participation in the learning process emerge in research as consistent predictors of the educational success of children in out-of-home care (Dill et al. 2012). In this regard, the YiPPEE Project (Jackson and Cameron 2012), funded by the European Commission, identified high academic expectations as one of the most influential factors for the educational achievement and university enrollment of minors in residential care institutions. This research considers previous findings and uses DFGs, educational action based on dialogic reading that provides a context of interactive learning that contributes to preventing GBV. On the one hand, numerous scientific studies have demonstrated positive improvements at cognitive, academic, emotional, and social levels (Flecha 2015). On the other hand, as developed in this section, evidence also exists of the effectiveness

2 For more information, see: “Women's rights and the COVID-19 Pandemic". Available online: https://www.coe.int/en/web/ genderequality/women-s-rights-and-covid-19 (accessed on 20 May 2020). 
of dialogic reading in the context of DFGs in promoting sexual-affective relationships free of violence among adolescents (Racionero-Plaza et al. 2020).

\subsection{Dialogue as a Protective Factor against Gender-Based Violence}

A study on dialogic learning (Puigvert 2016) provides evidence that generating spaces for open dialogue on sexual harassment and GBV contributes to more egalitarian models of sexual-affective relationships. These interactive environments promote the development of collective reasoning and communicative competences, which are also considered factors that protect against violence by allowing the verbalization of what is happening, the identification of aggressions, the reporting of the often silenced harassment, and the taking of positions themselves by creating support networks around GBV survivors (Racionero-Plaza et al. 2018).

In today's societies, socialization toward violent behaviors still prevails and is transmitted from multiple contexts of enormous influence in the construction of an adolescent's identities (Chung 2007; Racionero-Plaza et al. 2020). However, participation in dialogic environments of interaction and the intersubjective creation of knowledge has been proven to enable many young people to initiate processes of personal change, in contrast to the traditional model that linked attraction and violence (Flecha-Fernández de Sanmamed et al. 2011). Evidence from research shows that open dialogic spaces make it possible to build and share critical reflections on both the attitudes and behaviors that used to be more attractive in sexual-affective relationships and why this frequently happens. These types of debates and arguments provide important mechanisms for participants to identify the characteristics of egalitarian relationships free of all types of violence; therefore, open dialogic spaces allow adolescents to acquire important tools on how to eradicate violence (Foshee et al. 1998; Kast et al. 2015). The dialogic system also allows adolescents to contrast the debates with personal experiences while considering the possibility of transforming and improving their relationships on the basis of freely electing the people to whom to be close, constituting their environment of social interactions.

Dialogic reading has also been proven to favor critical accessibility to memories about sexual-affective relationships. This type of reading enables forward-looking thinking that could act as a preventive factor to avoid falling back into coercion and violent relationships in the future, increasing their critical awareness of the coercive discourse that often induces attraction to violence. According to this social perspective on memory research (Hirst and Rajaram 2014), evidence exists on the fact that making this scientific knowledge accessible to adolescents allows them to contrast it with their experiences through an egalitarian dialogue that succeeds in transforming thoughts and memories. This process provides positive results as a protective factor against GBV, "weakening the connection between attraction and violence" (Racionero-Plaza et al. 2018, p. 10). The application of the memory plasticity approach, although already developed from neuroscience and biology (Bailey et al. 2015; Ramón y Cajal 1894), is a novel finding in the field of prevention of GBV and education (Racionero-Plaza et al. 2020).

\subsection{Dialogic Feminist Gatherings and Preventive Socialization of Gender-Based Violence}

DFGs are "egalitarian dialogues focused on the transformation of the language of desire to create possibilities for women who wish to question desires imposed by patriarchal societies by tending to orient these desires toward nonviolent relationships" (Puigvert 2016, p. 190). These dialogic gatherings are based on the principles of dialogic learning (Barros-del Río et al. 2020), the contributions of dialogic feminism (Botton et al. 2005), and the preventive socialization against GBV (Gómez 2015). In this sense, solidarity, equality, freedom, and inclusion are highlighted as elements to build more just, equitable, and violence-free environments and societies. First, "solidarity" is important for creating support networks capable of preventing situations of harassment and violence and empowering survivors, proving their effectiveness in reducing the probabilities of future revictimization. Second, the struggle for "equality" in its most radical sense involves the transformation to overcome injustice and eradicate oppression from the value and respect for differences. Third, the defense of "freedom" is for everyone 
and his or her decisions in all areas of life. Finally, the "inclusion" of all voices, especially those of women who have traditionally been excluded by a hegemonic discourse, does not respond at all to the values embodied by feminism.

DFGs aim to prevent and overcome GBV. Therefore, a dialogue is established on elements that the scientific literature identifies as risk factors in everyday interactions, such as the attraction to violent masculinities or the opposition between the language of ethics and the language of desire (Ríos-González et al. 2018), which used to be manifested in communicative acts among adolescents. In the context of dialogic gatherings, the principle of communicative acts is established and is aimed at contrasting women's experiences and interpretations with scientific knowledge on preventing and overcoming GBV. This dialogic methodology allows the girls to have a say in searching for solutions to concrete problems (Torras-Gómez et al. 2019). This fact underlined the aim of reaching consensus, contributing to modifying previous conceptions that may represent socialization toward violence, and enriching the interpretive discourse to ensure the arguments' scientific validity.

Dialogic communicative acts through DFGs help to prevent and overcome GBV experiences by increasing participants' abilities to identify violence and its causes, enhancing egalitarian interactions, and promoting a freer and more informed election of their sexual-affective relationships. Along this line, reflections resulting from interactions among a diversity of people can modify the self-perception about harassment and abuse, contributing to a re-evaluation of concrete situations that may have led to violence, while enabling not only a personal change but also its extension to other agents of their context (Ramis et al. 2014). The very process of interactions through DFGs promotes the transformation of the risk factors of victimization and increases reflection on the socialization processes that can lead to preventing and overcoming GBV.

Without a doubt, at the scientific level, GBV among minors and adolescents is a concerning reality today. Crooks et al. (2019) offered an extensive review of the most effective programs for GBV prevention in the last 25 years but also identified serious gaps for vulnerable groups suffering victimization, such as minors and adolescents in out-of-home care, whose high risk is widely documented. This study contributes to filling this gap by bringing a successful educational activity, such as DFGs, to the context of residential care institutions. Doing so means approaching the concept of preventive socialization (Duque et al. 2015) for this vulnerable group and the scientific notion of the social origin of attraction (Gómez 2015), which represents an internationally already studied approach and allows for GBV situations for youth to be prevented and overcome from their earliest socialization.

\section{Materials and Methods}

This work was based on the principles of the Communicative Methodology (CM) (Gómez-González et al. 2010). This research perspective conceives that reality is to be studied as a set of meanings built through the dialogical interaction between all people involved. Therefore, the research conducted in this study through the CM focuses on the deep transformation that all participants achieve together in relation to GBV through language, dialogue, and interactions in the DFGs, mediated by scientific knowledge on GBV prevention.

Our study is developed through a qualitative methodological approach in its broadest sense, through bibliographic reviews and documentary analyses of the existing scientific literature on the state of the problem. Through the CM, this study conducted Communicative Daily life Stories and Communicative Focus Groups, which are subsequently explained, in the development of the Procedure section. Empirical data obtained from 15 case studies indicated that DFGs are one of the most successful actions for GBV prevention. Each case study involved 7 DFGs with adolescents, social workers, and researchers. In addition, 2 Communicative Focus Groups with all participants are included as are 3 Communicative Daily Life Stories with adolescents and social workers. Thus, our qualitative method is based on the case study method and considered the narratives of the people involved, all from a communicative perspective according to the Communicative Methodology principles (Gómez-González et al. 2010). 
Regarding the research impact on GBV and overcoming it, the design through the CM has been crucial for this analysis. It already proved its impact, and it has even influenced legislative progress in Spain in the field of prevention and creation of social movements to support survivors (Gómez-González et al. 2010; Gómez-González 2019). Similarly, in research on GBV, the very dialogue between researchers and the people being researched constitutes a basic procedure for analysis. The interview is not a question-answer format; rather, it consists of an egalitarian dialogue, in which the research brings the scientific knowledge, and the survivor, in this case, brings the real experience of a fact. Together, they construct the knowledge through equalitarian dialogue based on validity arguments. Additionally, the social construction of survivors' interpretations is also the result of dialogic processes between them and other persons with whom they interact in their daily lives (Ramis et al. 2014). This is how the construction of a narrative of stories from the daily lives of adolescents occurs.

This section explains the sociodemographic profile of the participants, the phases that shaped the procedure, and the data collection techniques used. Finally, the categories and subcategories in the data analysis are described.

\subsection{Participants}

The sample collected by this study involved fifteen adolescent girl participants whose profiles are detailed in Table 1. These adolescents, aged 15-18 years, find themselves living in out-of-home care because of serious issues related to a lack of family protection. They live in a residential care institution that is specifically intended to carry minors. At the institution, social workers developed a program aimed at preparing them for adult and independent life, strengthening responsibility skills, and habits of autonomy.

Table 1. Profiles of research participants.

\begin{tabular}{|c|c|c|c|}
\hline Pseudonym & Age & Educational Level & Personal Background \\
\hline A & 15 & Vocational training & Survivor of lack of protection and family violence \\
\hline B & 16 & Adapted Secondary School & Survivor of sexual assault in the family environment \\
\hline $\mathrm{C}$ & 17 & Vocational training & Survivor of family abuse and record of drug abuse \\
\hline $\mathrm{D}$ & 17 & Transition to Adulthood Program & Survivor of lack of protection and family violence \\
\hline $\mathrm{E}$ & 17 & Upper Secondary School & Survivor of lack of protection and family emotional abuse \\
\hline $\mathrm{F}$ & 16 & Upper Secondary School & Survivor of lack of family protection \\
\hline G & 18 & Vocational training & Survivor of sexual assault in the family context \\
\hline $\mathrm{H}$ & 15 & Adapted Secondary School & Survivor of lack of family protection \\
\hline I & 17 & Secondary School & Survivor of gender-based violence \\
\hline $\mathrm{J}$ & 18 & Vocational training & Survivor and perpetrator of family violence \\
\hline $\mathrm{K}$ & 18 & Secondary School & Survivor of sexual assault in the family context \\
\hline $\mathrm{L}$ & 15 & Adapted Secondary School & Survivor of family neglect and record of drug abuse \\
\hline M & 15 & Secondary School & Survivor of lack of protection and family violence \\
\hline $\mathrm{N}$ & 17 & Vocational training & Survivor of family neglect and record of drug abuse \\
\hline $\mathrm{O}$ & 16 & Adapted Secondary School & Survivor of lack of family protection \\
\hline
\end{tabular}

\subsection{Procedure}

The present study was conducted in four phases. In the first phase, we set up a Communicative Focus Group for initiating dialogue and reflecting on the documentary, "Voices against the silence" (Aguilera and Pérez-Cabezas 2018). The documentary focused on breaking the silence on GBV using the voices of the three main victims and other testimonies.

In the second phase, the DFGs were carried out during seven sessions over seven months. Each session lasted for two hours, and all of them were audio recorded. The adolescent girls started reading the book, "Radical Love: A Revolution for the 21st Century" (Gómez 2015), which provides scientific explanations of the social origin of love and the processes of attraction and election that play a key role in sexual-affective relationships, violence, and ways to overcome them. A social worker moderated the gatherings and took turns speaking in each DFG. Two researchers participated in the 
egalitarian dialogue, bringing from dialogic feminism the scientifically validated contributions to overcoming GBV. The reading of the "Radical Love" book deeply connected with the participants' life stories and contributed to linking, through the dialogues conducted, personal experiences with social changes while considering the scientific contributions to overcoming socialization toward GBV.

In the third phase of the research, a final Communicative Focus Group was conducted with the aim of dialoguing and reflecting on the past months of sharing DFGs. The researchers offered to all of the participants and social workers the option to share their feelings and opinions on developing DFGs. Finally, these data were completed with three Communicative Daily Life Stories. One of the stories was with the female social worker with the greatest involvement in the research and the highest level of attendance at the DFGs sessions. The other two Communicative Daily Life Stories were conducted together with two of the minors who participated in the DFGs sessions for the longest period.

Finally, the fourth phase included the data analysis conducted using the established categories and subcategories for the preventive socialization for GBV, as explained in the following section.

All techniques in data collection were recorded and transcribed literally, including overlaps. The person conducting the transcription process was the same who conducted the interviews and the focus groups. This is helpful both to deeply transcribe the text and the messages transmitted but also to maintain the intimacy and anonymity of such a sensitive matter. In addition to this, notes were collected in written form to consider prosodic communicative behaviors and all communicative acts. Indeed, this is a characteristic of the CM, which analyzes both verbal and non-verbal language, as well as the social context of the communicative interaction. This allowed us to identify which types of interactions and dialogues contribute to transforming and improving reality through implementing DFGs and which do not.

All of these dialogues with the participants did not aim to develop a biography; rather, they jointly constructed a narrative of the adolescents' daily life stories. The narrative would reflect aspects of the present and the past and, above all, expectations for the future. In this analysis, people who investigate and conduct the narrative placed themselves on equal terms to facilitate their everyday lives, which contrasted with the scientific knowledge on the subject studied. In this case, the preventive socialization against GBV and the transformations were potentially derived from participation in dialogic spaces of reading through DFGs.

\subsection{Data Collection}

The study presented was conducted during the year 2018 and beginning of 2019. The data collection techniques included Communicative Focus Groups, Dialogic Feminist Gatherings, and Communicative Daily Life Stories. The very purpose of the research justified its development through CM, as well as the use of qualitative techniques for data collection with a communicative orientation. The different techniques used for data collection contribute to the triangulation of the data obtained (Denzin 1970), allowing them to be approached with the different instruments for the qualitative analysis, which provides a greater reliability of the results obtained (Patton 2002). In this line, connecting the approach of Norman Denzin with our research, we cover the triangulation aspect by triangulating the data and the results between the focus groups, the daily life stories, and the researcher who performed the fieldwork and collected the data. This person observed each session of the dialogic feminist gathering, while gathering notes in the field diary. The triangulation also included the social workers' perspectives, as people who live with the minors day by day, knowing their needs and concerns.

Another element for triangulation was the design of research around three major scientific fields: (1) the inequality and vulnerability of children in out-of-home care, (2) the preventive socialization of GBV in minors and adolescents, and (3) DFGs as one of the most successful actions for GBV prevention. In addition, the large number of dialogues on deep themes about the preventive socialization of GBV that have been constructed in each of the seven DFGs make it possible to base research on dialogical communicative acts, placing in the foreground the search for the joint interpretation of reality and ways to improve it. 


\subsubsection{Communicative Focus Groups}

Two Communicative Focus Groups were conducted with the women participants in the research, involving fifteen adolescent girls and two social workers of the residential care institution. The first session of the focus group was carried out before the intervention, in June 2018, and the second session was held after seven months of sharing DFGs. Both sessions followed the aim of developing an egalitarian dialogue in which scientific research on the preventive socialization of GBV could be contrasted with the knowledge and experiences of the participants, before and after the DFG intervention. The first focus group also inspired the category elaboration, later contrasted with the research and the intervention.

\subsubsection{Dialogic Feminist Gatherings}

The DFGs were carried out during seven sessions over seven months, involving fifteen adolescent girls and five social workers. This made possible the shared construction of meaning around five main issues for the preventive socialization of GBV through the reading and discussion of "Radical Love" (Gómez 2015): (1) attraction and election theories in sexual-affective relationships; (2) transformative theories about love in the 21st century; (3) differences between traditional and alternative sexual-affective relationship models; (4) the reality of sexual-affective relationships from the perspective of adolescent voices; and (5) basic competences for the development of satisfying, egalitarian, and violence-free sexual-affective relationships.

\subsubsection{Communicative Daily Life Stories}

Three Communicative Daily Life Stories gave a reflective account of their daily life, describing aspects of the present and the past and, above all, expectations for the future. This involved two adolescent girls and one social worker. The Communicative Daily Life Stories were used to obtain more detailed information about the social impact of DFGs on their daily lives in a climate of trust and egalitarian dialogue where we shared thoughts, reflections, interpretations, and experiences around GBV.

\subsection{Data Analysis}

The different techniques used in the research contributed to the triangulation of the data obtained, allowing the results to be approached using several qualitative analysis instruments. By contrast, the significant dialogue on important and deep topics related to the preventive socialization of GBV built into each of the recorded DFGs made it possible to base the research on dialogic communicative acts, placing in the foreground the joint interpretation of reality through egalitarian dialogue. Through these techniques and the interactive process of understanding followed at every DFG, we shared thoughts, feelings, reflections, interpretations, and ways of acting and solving different situations in an environment of trust that evidence the impact of dialogic reading in the lives of these girls.

The analysis of all of the information collected aims to overcome inequalities by also identifying the factors that reproduce them. To this end, we collected the two components of the CM for the analysis: (1) the exclusionary dimension, which refers to the barriers that are hindering a type of socialization toward egalitarian and nonviolent sexual-affective relationships, and (2) the transformative dimension, which evidences the acquisition of competences for the preventive socialization against GBV through dialogic reading spaces. Thus, the CM itself is based on the exclusionary and the transformative dimension for all the analysis conducted through this methodology. The study presented is part of wider research, and this article focuses on this second dimension. All of the data collected have been organized according to specific categories and subcategories established through the social theory of sexual-affective relationships for the preventive socialization against GBV (Gómez 2015), as reflected in Table 2. 
Table 2. Categories and subcategories in data analysis (Gómez 2015).

\begin{tabular}{|c|c|c|}
\hline \multicolumn{3}{|c|}{ Preventive Socialization of Gender-Based Violence } \\
\hline Competencies in ATTRACTION & Competencies in ELECTION & Competencies for EQUALITY \\
\hline Subcategories & Subcategories & Subcategories \\
\hline Social origin of love & $\begin{array}{l}\text { Intersubjective or communicative } \\
\text { election of sexual-affective relationships }\end{array}$ & $\begin{array}{l}\text { Knowledge of the internalization } \\
\text { of power hierarchies }\end{array}$ \\
\hline Rejection of unequal relationships & $\begin{array}{l}\text { Elimination of situations in which desire } \\
\text { is opposed to reason }\end{array}$ & $\begin{array}{l}\text { Development of equal } \\
\text { sexual-affective relationships }\end{array}$ \\
\hline Attraction to egalitarian relationships & $\begin{array}{c}\text { Election based on the transformative } \\
\text { definition of love }\end{array}$ & \\
\hline
\end{tabular}

The units of analysis used for this research consisted of considering each of the categories and subcategories mentioned above, referring to sexual-affective relationships for the preventive socialization against GBV (Gómez 2015). These are in line with interactive sequences alimented based on a dialogical interaction process through dialogues and communicative acts in Communicative Focus Groups, DFGs, and Communicative Daily Life Stories. This responds to an inductive method in the data analysis, where there was already prior scientific research that had established the categories and subcategories for analyzing preventive socialization against GBV (Gómez 2015). According to this, the three elements are defined. First, competencies in attraction refers to transforming the traditional sexual-affective relationship model from an egalitarian perspective aimed at preventing and overcoming GBV. This element means being aware of the enormous social influence on an individual's predisposition to being attracted to models of masculinity or femininity that respond to certain values rather than violent and pre-established aesthetic criteria throughout history in each society. Second, competencies in election refers to interactions and dialogues based on claims of validity and that aimed to choose nonviolent sexual-affective relationships. This element implies knowing that when someone who does not have egalitarian values attracts us, the best decision for the present and future is not to choose him or her but, rather, to run away. Finally, competencies for equality involves recognizing and understanding how people internalize the hierarchies of power from birth through all of the agents of socialization of our environment. Simultaneously, this element implies acquiring resources to advance toward more egalitarian and democratic relations in which the validity of the arguments is placed above the position of the authoritarian power of the one who issues them. The dialogues between the participants in each of the DFGs have been analyzed and classified according to the corresponding subcategories, as detailed in the results section, to evaluate the acquisition of the three competencies.

\section{Results}

The results obtained in this study are solid in affirming that the DFGs are an effective educational mechanism for the preventive socialization against GBV in minors and adolescents in out-of-home care. The set of dialogues acknowledged between all of the participants demonstrates the acquisition of competencies in attraction, election, and competencies for equality that are identified in the scientific literature as protective factors against GBV. This section shows the results described in each subcategory of the analysis. Both in the design of the case study and in the evaluation of its results, special consideration has been given to obtaining social impact, so to improve the lives of the people researched-that is, to ensure, from the research methodology itself, a focus on results to improve this social reality of inequality and violence. To this end, the narratives of those researched help to fulfill this aim. 


\subsection{Competences in Attraction}

\subsubsection{Social Origin of Love and Socialization in the Traditional Relationship Model}

Critical dialogues between the female participants recognized the social origin of love. This fact offers new opportunities for preventive socialization against GBV by rejecting the spontaneous and irrational perspective of relationships while recognizing the capacity and freedom of all people to build the kind of personal relationships they wish to live. To support this argument, one girl of the study stated:

Come on, that attraction... Both attraction and love is a personal thing, it does not depend on a "Cupid" coming here to give you a crush or being an attraction and destiny and things like that. We simply decide on the kind of love, in which way and with what premises we have a relationship.

(F, 16 years old)

This competence also implies that the social character of sexual-affective relationships makes it "almost impossible to reprogram ourselves alone" (E, 17 years old). Thus, it is especially relevant to know how to identify it, within our own environment, and one of the adolescents expresses it just as clearly: "there are people who do not help you and other people who help you to change and to get out of a bad situation" (C, 17 years old).

Through the knowledge constructed during the DFGs, the girls identified two main consequences that, throughout history, have been produced by this traditional socialization. The first is the deprivation of women's freedom related to the possibilities enjoyed by men. The second is the limitation of women's scope of action, traditionally limited to a strictly family or private environment. In addition, under traditional socialization, the attraction toward violent models of masculinity is identified. This attraction comes because of an unequal consideration of dominant attitudes according to whether they are from a man or a woman and the phenomenon of the mirage of upward mobility (Duque et al. 2015) is clearly identified by the girls: "They do not see us the same, it is a lie... Womanizers are cool, and women are sluts and banners" (C, 17 years old), or, "It's the law of the key, which I've already said again. A good key is one that opens many doors, but the doors that have been opened many times are the ones that are useless" (A, 15 years old).

\subsubsection{Rejection of Unequal Relationships}

Participants expressed that the rejection of unequal relationships represents a key decision for the transformation of attraction from the traditional socialization model to the alternative model of sexual-affective relationships. This statement becomes stronger as the girls share the dialogues in each of the DFGs:

- Yes, it's just that for one night you can end up very badly. You have to know how to do it with so that you don't have to tell the whole neighborhood and you're already fucked. Even if it's just one night, let's make it worth it! (A, 15 years old).

- $\quad$ Make it always special $(\mathrm{O}, 16$ years old).

- It's just that it's literally. Let's make it five minutes, but five minutes worth remembering (I, 17 years old).

- That's enough! How do you get attracted to a person who fucks up your life? Handsome? No, a shitty person! (A, 15 years old).

As is observed in this intervention, the girls supported themselves through a multitude of dialogues to reject boys who respond to the traditional dominant model of masculinity. They take off the potential attraction associated with these types of boys in both stable and sporadic relationships: "When they hurt me, they hurt me. And that is how it is... If you have hurt me once, I take into account that it will not be the last time" (C, 17 years old). 


\subsubsection{Attraction to Egalitarian Relationships and Linking Passion and Friendship}

This is one of the most significant steps for socialization in the alternative model of sexual-affective relationships. On the one hand, in the adolescents' reflections about the attraction toward people who respond to egalitarian models, the dialogue and the social interactions are always identified as keys to the acquisition of this competence. This statement is supported by the following example:

I think you could start by changing your environment. That is to say, your people, and then already... Because in this way, in small groups, we can make a group, a group in quotes, like... And, in this way, more or less, something in society can change.

$$
\text { (C, } 17 \text { years old) }
$$

On the other hand, in the contexts of DFGs, attraction is defined on the basis of both aesthetic components and ethical values; therefore, it is clearly linked to those egalitarian people, as the women interviewed claimed:

- What is attraction? Does this mean that you like it? Does it mean you are "on fire"? (D, 17 years old). - Yes, but not only physically, but also personally, in terms of thought and goodness... (F, 16 years old).

- We should get to have it all (L, 15 years old).

These dialogues include the previously described competences as a whole. Because attraction is social, it is a matter of reaching the critical capacity to identify the components of traditional socialization, to reject in all social spheres those who despise and mistreat, to build attraction toward those who represent egalitarian values, and to necessarily link feelings of passion and friendship, in both stable and sporadic relationships.

- Yes. It strikes me that in all media they separate whether you are passionate or sweet and kind. There is a tendency to separate passion from being a sweet and kind person, and one must stop believing that they are opposites (F, 16 years old).

- $\quad$ And enjoy it! (I, 17 years old).

\subsection{Competences in Election}

4.2.1. Intersubjective or Communicative Election of Sexual-affective Relationships and Election Based on Claims of Validity

In the DFGs, all of the participants identified the fact that prioritizing the intersubjective or communicative election of sexual-affective relationships could help prevent the beginning of unequal relationships. Therefore, their dialogue and manner of sharing topics offered each other support to overcome situations in which it is difficult to choose the best option in terms of science and ethics: "So you call me! If we tell each other, it helps" (E, 17 years old).

Once an election is made on the basis of validity claims, they know that they have complete freedom as to personal taste or preferences in the aesthetic field. The criteria taken into account are from the scientists of the social theory of love and the preventive socialization against GBV, and the ethical criteria, which allow us to choose on the basis of the transforming definition of sexual-affective relationships that overcomes the social pressure exerted in the opposite direction:

- $\quad$ Sometimes, you go for the one who treats you badly. You know, but he's the coolest one, you think he is cute (C, 17 years old).

- From what you've said, I think we get that boy because if you get the good boy, your friends are going to say: "Why are you with this one if others are better looking?" ( $\mathrm{H}, 15$ years old).

- That's what I wanted to say. They've put us like glasses that don't let us see the truth and on the real scale we go down, we look like shit (C, 17 years old). 


\subsubsection{Elimination of Situations in Which Desire is Opposed to Reason}

Having social surroundings that promote egalitarian relationships helps prevent situations in which desire is opposed to reason. In this case, for example, the different girls identified how the election of destroying all types of contact with nonequalitarian people decisively influences the diminishment of the attraction toward violence:

- I have chosen point one of the eighty-nine [she reads]. The thing about transforming attraction, because you choose those with traditional values and there are always problems, you have a hard time and the days of not seeing him make you recover ( $\mathrm{D}, 17$ years old).

- Yes, that the person's absence is what makes you realize ... (A, 15 years old).

- $\quad$ That, that you can do by not seeing him so that it goes away, and it goes away (D, 17 years old).

- As you choose wrong, but if you decide to spend days without seeing him, you realize better that this is not what you want for you (C, 17 years old).

\subsubsection{Election Based on the Transformative Definition of Love}

Election based on the transformative definition of love implies valuing sexual-affective relationships only in terms of the respect with which the people involved in them are treated and combines scientific, ethical, and aesthetic criteria. DFGs provide participants with the transforming definition of love in the 21st century, which contains dialogue, negotiation, and consensus in all sexual-affective relationships and the absence of violence in all interactions among the people involved. Now, they know it:

The fact is that what we sometimes look for in a stable relationship seems to be simply some tenderness, friendship, I don't know what, and we forget about passion. And when we want a sporadic relationship what we look for is simply passion without a person treating us well. So, the goal is to take all those characteristics for both a casual and a steady relationship ... Why don't we make good choices in casual relationships, too? By choosing a person who treats us well, who treats us with respect. We have to learn to choose that guy and push the pimp one away.

(F, 16 years old)

\subsection{Competences for Equality}

\subsubsection{Knowledge of the Internalization of Power Hierarchies and Development of Critical Spirit}

Many dialogues among the girls in the DFGs were aimed at reviewing their entire environment, including the family context. This review involves recognizing at some point that, when the influence exercised is not in line with egalitarian values, the people themselves possess the final decision to change the socialization in the elements that do not benefit him or her, as this 17-year-old girl said:

Family can raise you in one way, but you can do the opposite, for better or for worse.

$$
\text { (C, } 17 \text { years old })
$$

This competence also underlines the importance of placing gender interactions in an egalitarian perspective through which both women and men take equal responsibility for creating nonviolent relationships. One of the girls expressed it as follows: "We need to change both girls and boys in the way we act so that there are no more GBV cases going on in the world" (B, 16 years old).

\subsubsection{Development of Equal Sexual-affective Relationships}

Finally, for socialization to prevent and overcome GBV, getting involved in the development of equal sexual-affective relationships is essential. Along this line, the DFGs have opened up a multitude of dialogues about the importance of, for example, consent or solidarity networks as keys to gender equality. Adolescent girls also included here many dialogues on the transformative power of human 
agency, assimilating that the construction of egalitarian or nonegalitarian values is social and, therefore, can be transformed. In this sense, a door of hope is opened when these girls place themselves as an element of support for each other, highlighting women's solidarity and the importance of generating support networks to move toward nonviolent relationships.

\section{Discussion and Conclusions}

The World Health Organization warns that physical or sexual violence against women is a global health problem of epidemic proportions, affecting more than one-third of all women worldwide (World Health Organization et al. 2013). The severity of this reality in all current societies lies in both the increase in the number of victims and the decrease in their ages (Adhia et al. 2019; Duque et al. 2015). The scientific literature places the origin of GBV in socialization on models of traditional sexual-affective relationships and the attraction toward violence (Chung 2007; Puigvert et al. 2019; Caridade et al. 2020). This process, which is socially acquired, can also be socially transformed by influencing dialogues and interactions that promote those competencies in attraction, election, and equality. These factors contribute to transforming socialization toward models of egalitarian and nonviolent relationships (Puigvert 2016; Racionero-Plaza et al. 2020). The consideration of these social and scientific impacts has shaped the development of this research, in which the dialogic reading through DFGs has been analyzed to provide more evidence of its potentiality as a scientific measure for the preventive socialization against GBV. Dialogic reading through DFGs has been implemented in a residential care institution with minors and adolescents whose situations of vulnerability and risk of exclusion are widely documented, placing their causes in both the lack of family protection and the impact of institutionalization on their development (McCall 2013; Friesem and Levchak 2019).

Research on the implications of dialogic reading in preventing and overcoming GBV reveals that this space for dialogue and critical reflection is highly effective in transforming the communicative acts that link attraction and violence and establish a barrier between the language of desire and the language of ethics, resulting in different studies on the risk factors of victimization. This classification among ethics, science, and aesthetics was proposed by Plato in 380 B.C. and discussed by Weber (1978), Habermas (1987), and Flecha (2000). The last study raised how the current crisis of meaning that is loose in human relations has its origin in the separation of these three areas, which is strongly involved in increasing GBV in sexual-affective relationships.

The results of this research are consistent with those of previous exploratory studies that showed the benefits of Dialogic gatherings on their feelings and self-conceptions and created new and exciting meaning in their lives (García-Yeste et al. 2018). In our case, participants reflected that DFGs provide them with elements for preventive socialization against GBV. In addition, the study shows that participation in DFGs contributes to raising awareness and improving the behavior of competencies in attraction, election, and gender equality, which act as preventive factors for violence socialization among adolescents. In line with the reviewed scientific literature, this article provides new evidence of the potential of DFGs in the preventive socialization against GBV, also in contexts of out-of-home care. In the DFGs, the validity of the arguments is based on scientific and ethical criteria, taking attraction from nonegalitarian relationships and destroying dialogues that link love and violence to provide adolescent girls with tools to overcome the coercive discourse and the social pressure that is exerted on the attraction to models of violent masculinities. This work also focuses its analysis on relating the competencies of the social theory of love (Gómez 2015) for attraction, election, and equality, which promotes valuable knowledge when choosing relationships free of violence and guides action toward prevention from the principles of dialogic feminism: solidarity, equality, freedom, and inclusion.

Among the less-researched transformations is the contribution of dialogic reading spaces to the construction of references and the creation of solidarity support networks that achieve socioeducational transformations from very different spheres-from the family to the community (Soler-Gallart 2015). The content of the dialogues that arise around DFGs is already, by itself, a motivating element (Reed and Vaughn 2012). When "the lives and identities of the students (...) are intentionally interwoven with 
the texts" (Gritter 2011, p. 446) through intersubjective interpretation, multiple possibilities are opened up to recover vital meaning and to create solidarity support networks that contribute to generating social improvements. The data collected show that minors support each other and share deep concerns, building bonds of solidarity that go beyond this space and, sometimes, even become true friendships. This is crucial because the scientific literature has already demonstrated the influence of social support and communicative interactions between personal networks of trust on both emotional well-being and mental health and happiness (Dorrance-Hall et al. 2019; Waldinger and Schulz 2010).

In gathering after gathering, a network of trust, support, and solidarity has been generated among the 15 women participants. In many cases, this process has acted as a protective factor against the making of decisions that could be contrary to their well-being. Peer support networks also have the potential to prevent and curb situations of harassment and violence and offer the victim, if necessary, support in facing and overcoming traumatic experiences or breaking the silence surrounding GBV. In many cases, the structural elements or institutional barriers make it difficult to identify the problem and recognize that some situations do not truly happen in a preferred manner. Therefore, the strong network of support generated in each of the DFGs generates the courage for them to dare to change the course of their lives, starting with the rejection of toxic relationships around them.

In the data analysis, we have taken into account whether this study was also affected by the problem of compressive sociology - because of its characteristics-when attempting to distinguish the plausibility of the stories or whether a discrepancy exists-because of social convenience-among what participants truly think, what they say, and whether what they say they do because it is what they are expected to say or because they feel that way. However, the scientific literature on autobiographical memory challenges this limitation and shows evidence that the strongest impact on human memory is not produced by the memory itself but by the manner in which the person recodes and processes it each time it is shared in dialogue with other people (Stone et al. 2010).

This paper aimed to increase the scientific evidence in this field and to help overcome serious human rights violations against adolescents in out-of-home care and examined the positive impact of interactive learning environments by implementing DFGs in a residential care institution with a group of adolescent girls. In addition, this paper aimed to improve their education and help prevent and overcome the potential GBV by developing protective factors to prevent future revictimization. This study shows that dialogic reading from the dialogic feminist perspective allows young people from a public care background to have more possibilities to dream of a better future that is free of violence.

This work is dedicated to each of the minors who, gathering after gathering, have been feeling that they have the right to dream of a better future and with the highest expectations. One of the girls dreams of studying medicine; another, of learning English because she wants to live in London; another girl dreams of studying for scientific conferences or writing an article in the digital daily newspaper called "Diario Feminista". ${ }^{3}$ Nevertheless, all of them share the dream of having relationships free of violence, which they are already beginning to build. Beyond their analysis and scientific contribution, the value of this research is measured by their improvement and by the strength of their voices-in the manner in which, gathering after gathering, dialogues turn difficulties into possibilities and their memory accumulates more and more words, dialogues, and dreams that set the path toward a better future. As one of them said: "You never leave a DFG the same way as you came in" (F, 16 years old).

\section{Limitations}

Whereas our data and results show a link between increased awareness of gender-based violence and girls' reflections on preventive socialization against it and self-improvement on election, attraction, and equality, this study was not designed according to the quasi-experimental design (pre-post test).

3 For more information, see: https://eldiariofeminista.info/. 
From the starting point of these girls and their perceptions, we could not totally affirm the correlation of these elements with their impact, neither do we pretend to do so; however, this does not mean that it does not exist; this only means that it has not been studied in this way.

Without aiming to show the effect of interventions, the results of this study open the floor for new research to explore the effect of the intervention considering a quasi-experimental design.

Author Contributions: All authors contributed to the development of this article. To provide some individual contributions, conceptualization and methodology was conducted by M.S. and A.A.; validation and formal analysis were elaborated by E.R. and A.V.; resources and data curation, A.A. and M.S.; writing-original draft preparation, M.S. and A.V.; writing-review and editing, E.R. and M.S.; visualization and supervision, A.A., A.V. and E.R. All authors have read and agreed to the published version of the manuscript.

Funding: This research received no external funding.

Conflicts of Interest: The authors declare no conflict of interest.

\section{References}

Adhia, Avanti, Mary A. Kernic, David Hemenway, Monica S. Vavilala, and Frederick P. Rivara. 2019. Intimate Partner Homicide of Adolescents. JAMA Pediatrics 173: 571-77. [CrossRef] [PubMed]

Aguilera, Curro, and Enrique Pérez-Cabezas. 2018. Voices against the Silence. Spain: Radio Televisión Española RTVE. Available online: https://www.rtve.es/alacarta/videos/documentos-tv/documentos-tv-voces-contrasilencio-subtitulado-ingles/4072140/ (accessed on 15 May 2020).

Bailey, Craig H., Eric R. Kandel, and Kristen M. Harris. 2015. Structural components of synaptic plasticity and memory consolidation. Cold Spring Harbor Perspectives in Biology 7: 1-29. [CrossRef] [PubMed]

Baldwin, Helen, Nina Biehal, Linda Cusworth, Jim Wade, Victoria Allgar, and Panos Vostanis. 2019. Disentangling the effect of out-of-home care on child mental health. Child Abuse E Neglect 88: 189-200. [CrossRef]

Barros-del Río, María A., Pilar Álvarez, and Silvia Molina. 2020. Implementing Dialogic Gatherings in TESOL teacher education. Innovation in Language Learning and Teaching. [CrossRef]

Botton, Lena de, Lídia Puigvert, and Montserrat Sánchez-Aroca. 2005. The Inclusion of Other Women. Breaking the Silence through Dialogic Learning. Dordrecht: Springer. [CrossRef]

Brännström, Lars, Hilma Forsman, Bo Vinnerljung, and Ylva B. Almquist. 2017. The truly disadvantaged? Midlife outcome dynamics of individuals with experiences of out-of-home care. Child Abuse E Neglect 67: 408-18. [CrossRef]

Caridade, Sónia, Inês Pinheiro, and Maria A. Pimenta-Dinis. 2020. Stay or Leave Abusive Dating Relationships: Portuguese Victims' Reasons and Barriers. Social Sciences 9: 84. [CrossRef]

Chung, Donna. 2007. Making meaning of relationships: Young women's experiences and understandings of dating violence. Violence against Women 13: 1274-95. [CrossRef]

Crooks, Claire V., Peter Jaffe, Caely Dunlop, Amanda Kerry, and Deinera Exner-Cortens. 2019. Preventing Gender-Based Violence Among Adolescents and Young Adults: Lessons From 25 Years of Program Development and Evaluation. Violence against Women 25: 29-55. [CrossRef]

Denzin, Norman K. 1970. Sociological Methods. A Sourcebook. Chicago: Aldine Publishing Company.

Dill, Katharine, Robert J. Flynn, and Matthew Hollingshead. 2012. Improving the educational achievement of young people in out-of-home care. Children and Youth Services Review 34: 1081-83. [CrossRef]

Dorrance-Hall, Elizabeth, Jingbo Meng, and Reed M. Reynolds. 2019. Confidant Network and Interpersonal Communication Associations with Depression in Older Adulthood. Health Communication, 1-10. [CrossRef]

Duque, Elena, Ana Burgués de Freitas, Marcos Castro Sandúa, Marta Cortés Camacho, Ramón Flecha, Elisenda Giner, Liviu Catalin Mara, Carmen Martín Gómez, Patricia Melgar, Guiomar Merodio, and et al. 2015. IDEALOVE\&NAM. In Socialización Preventiva de la Violencia de Género. Madrid: CNIIE, Ministerio de Educación y Formación Profesional.

Flecha, Ramón. 2000. Sharing Words: Theory and Practice of Dialogic Learning. Lanham: Rowman \& Littlefield.

Flecha, Ramón. 2015. INCLUD-ED Consortium. Successful Educational Actions for Inclusion and Social Cohesion in Europe. London: Springer.

Flecha-Fernández de Sanmamed, Ainhoa, Cristina Pulido, and Miranda Chistou. 2011. Transforming violent selves through reflection in critical communicative research. Qualitative Inquiry 17: 246-55. [CrossRef] 
Flynn, Robert J., Nicholas G. Tessier, and Daniel Coulombe. 2013. Placement, protective and risk factors in the educational success of young people in care: Cross-sectional and longitudinal analyses. European Journal of Social Work 16: 70-87. [CrossRef]

Foshee, Vangie A., Karl E. Bauman, Ximena B. Arriaga, Russell W. Helms, Gary G. Koch, and George Fletcher-Linder. 1998. An evaluation of safe dates: An adolescent dating violence prevention program. American Journal of Public Health 88: 45-50. [CrossRef] [PubMed]

Friesem, Elizaveta, and Charisse C. Levchak. 2019. "I don't care" or "It's their fault": System justification and the lack of empathy as complementary obstacles to dealing with the modern sexism. Multidisciplinary Journal of Gender Studies 8: 256-80. [CrossRef]

García-Yeste, Carme, Regina Gairal, Ariadna Munté, and Teresa Plaja. 2018. Dialogic literary gatherings and out-of-home child care: Creation of new meanings through classic literature. Child \& Family Social Work 23: 62-70. [CrossRef]

Gómez, Jesús. 2015. Radical Love: A Revolution for the 21st Century. Barcelona: Hipatia, New York: Peter Lang.

Gómez-González, Aitor. 2019. Science with and for society through qualitative inquiry. Qualitative Inquiry, 1-7. [CrossRef]

Gómez-González, Aitor, Sandra Racionero-Plaza, and Teresa Sordé. 2010. Ten years of critical communicative methodology. International Review of Qualitative Research 3: 17-43. [CrossRef]

Gritter, Kristine. 2011. Promoting lively literature discussion. Reading Teacher 64: 445-49. [CrossRef]

Habermas, Jürgen. 1987. Theory of Communicative Action, Volume Two: Lifeworld and System: A Critique of Functionalist Reason. Boston: Beacon Press.

Hirst, William, and Suparna Rajaram. 2014. Towards a social turn in memory: An introduction to a special issue on social memory. Journal of Applied Research in Memory and Cognition 30: 77-97. [CrossRef]

Jackson, Sonia, and Claire Cameron. 2012. Final report of the YiPPEE project WP12. In Young People from a Public Care Background: Pathways to Further and Higher Education in Five European Countries. London: Institute of Education, University of London.

Kast, Nicole R., Marla E. Eisenberg, and Renee E. Sieving. 2015. The role of parent communication and connectedness in dating violence victimization among latino adolescents. Journal of Interpersonal Violence 31: 1932-55. [CrossRef]

Lum, Jarrad A. G., Martine Powell, and Pamela C. Snow. 2018. The influence of maltreatment history and out-of-home-care on children's language and social skills. Child Abuse \& Neglect 76: 65-74. [CrossRef]

McCall, Robert B. 2013. Review: The consequences of early institutionalization: Can institutions be improved? should they? Child and Adolescent Mental Health 18: 193-201. [CrossRef]

Patton, Michael Quinn. 2002. Qualitative Research and Evaluation Methods. Thousand Oaks: Sage.

Puigvert, Lídia. 2016. Female university students respond to gender violence through Dialogic Feminist Gatherings. International and Multidisciplinary Journal of Social Sciences-Rimcis 5: 183-203. [CrossRef]

Puigvert, Lídia, Loraine Gelsthorpe, Marta Soler-Gallart, and Ramon Flecha. 2019. Girls' perceptions of boys with violent attitudes and behaviours, and of sexual attraction. Palgrave Communications 5. [CrossRef]

Pulido, Cristina, Beatriz Villarejo-Carballido, Gisela Redondo-Sama, and Aitor Gómez-González. 2020. COVID-19 infodemic: More retweets for science-based information on coronavirus than for false information. International Sociology. [CrossRef]

Racionero-Plaza, Sandra, Leire Ugalde-Lujambo, Lídia Puigvert, and Emilia Aiello. 2018. Reconstruction of autobiographical memories of violent sexual-affective relationships through scientific reading on love: A psycho-educational intervention to prevent gender violence. Frontiers in Psychology 9. [CrossRef]

Racionero-Plaza, Sandra, Leire Ugalde-Lujambo, Guiomar Merodio, and Nerea Gutiérrez-Fernández. 2020. Architects of their own brain. Social impact of an intervention study for the prevention of gender-based violence in adolescence. Frontiers in Psychology 10: 3070. [CrossRef] [PubMed]

Ramis, Mimar, Noemí Martín, and Tatiana Iñíguez. 2014. How the dialogue in communicative daily life stories transforms women's analyses of why they suffered gender violence. Qualitative Inquiry 20: 876-82. [CrossRef]

Ramón y Cajal, Santiago F. 1894. The croonian lecture: La fine structure des centres nerveux. Proceedings of the Royal Society of London 55: 444-68. [CrossRef]

Reed, Deborah K., and Sharon Vaughn. 2012. Retell as an indicator of reading comprehension. Scientific Studies of Reading 16: 187-217. [CrossRef] 
Ríos-González, Oriol, Juan Carlos Peña-Axt, Elena Duque, and Lena De Botton. 2018. The language of ethics and double standards in the affective and sexual socialization of youth. Communicative acts in the family environment as protective or risk factors of intimate partner violence. Frontiers in Sociology 3: 1-9. [CrossRef]

Social Exclusion Unit. 2001. National Strategy for Neighbourhood Renewal: Policy Action Team Audit. London: Cabinet Office.

Soler-Gallart, Marta. 2015. Biographies of invisible "people who transform their lives and enhance social transformations through dialogic gatherings". Qualitative Inquiry 21: 839-42. [CrossRef]

Stone, Charles B., Amanda J. Barnier, John Sutton, and William Hirst. 2010. Building consensus about the past: Schema consistency and convergence in socially shared retrieval-induced forgetting. Memory 18: 170-84. [CrossRef] [PubMed]

Torras-Gómez, Elisabeth, Mengna Guo, and Mimar Ramis. 2019. Sociological Theory from Dialogical Democracy. International and Multidisciplinary Journal of Social Sciences 8: 216-34. [CrossRef]

UN Women. 2018. Turning Promises into Action: Gender Equality in the 2030 Agenda for Sustainable Development. UN Women Publications. Available online: https:/www.unwomen.org/en/digital-library/publications/2018/ 2/gender-equality-in-the-2030-agenda-for-sustainable-development-2018 (accessed on 20 May 2020).

Waldinger, Robert J., and Marc S. Schulz. 2010. What's love got to do with it? Social functioning, perceived health, and daily happiness in married octogenarians. Psychology and Aging 25: 422-31. [CrossRef] [PubMed]

Weber, Max. 1978. Economy and society. An Outline of Interpretive Sociology. Berkeley: University of California Press.

Wolfe, David A., Christine Wekerle, Katreena Scott, Anna-Lee Straatman, Carolyn Grasley, and Deborah Reitzel-Jaffe. 2003. Dating violence prevention with at-risk youth: A controlled outcome evaluation. Journal of Consulting and Clinical Psychology 71: 279-91. [CrossRef] [PubMed]

World Health Organization, Department of Reproductive Health and Research, London School of Hygiene and Tropical Medicine, and South African Medical Research Council. 2013. Global and Regional Estimates of Violence against Women: Prevalence and Health Effects of Intimate Partner Violence and Non-Partner Sexual Violence. Available online: https://apps.who.int/iris/handle/10665/85239?locale-attribute=es\& (accessed on 20 May 2020).

(C) 2020 by the authors. Licensee MDPI, Basel, Switzerland. This article is an open access article distributed under the terms and conditions of the Creative Commons Attribution (CC BY) license (http://creativecommons.org/licenses/by/4.0/). 